\title{
Pulmonary Rehabilitation Alters Ventilatory and Cardiac Performances Profile during Exercise in Moderate to Severe Copd: 5 Cases Report
}

\section{Murillo Frazão* and Wanessa Frazão}

Maria Caetano Fernandes de Lima St., 225, Tambauzinho, João Pessoa-PB, Brazil

\begin{abstract}
Background: COPD affects skeletal muscle system. Less efficient muscles generates higher ventilatory demand, which promotes a vicious cycle of dynamic hyperinflation and cardiac constraints, reducing functional capacity.
\end{abstract}

Aim: To investigate the effects of a pulmonary rehabilitation program, based on physical exercise, on ventilatory and cardiac performances profile.

Methods: 5 moderate to severe COPD patients were recruited. All patients were submitted to 8 week ( 5 times/ week) pulmonary rehabilitation program, composed by aerobic and resistance training. The patients performed a cardiopulmonary exercise test (CPET) before and after the program.

Results: Pulmonary rehabilitation changed ventilatory $(10.53 \pm 5.32$ vs. $28.97 \pm 12.07 \%, p<0.05)$ and cardiac consumption $(10.04 \pm 1.80$ vs. $22.88 \pm 10.36 \%, p<0.05)$ at $100 \%$ work rate. Pulmonary rehabilitation also increased ventilation $(20.6 \pm 3.3$ vs. $27.1 \pm 5.9 \mathrm{~L} / \mathrm{min}, \mathrm{p}<0.05)$ and oxygen pulse $(5.4 \pm 1.6 \mathrm{vs} .7 .5 \pm 1.9 \mathrm{ml} / \mathrm{beat}, \mathrm{p}<0.05)$ at $100 \%$ work rate, $\mathrm{VO}_{2}(610 \pm 110$ vs. $880 \pm 230 \mathrm{ml} / \mathrm{min}, \mathrm{p}<0.05)$ and work rate $(36.8 \pm 9.8$ vs. $55.6 \pm 14.8 \mathrm{~W}, \mathrm{p}<0.05)$.

Conclusion: A 8 week pulmonary rehabilitation program improved ventilatory and cardiac performances, probably as a result of dynamic hyperinflation reduction. Peripheral muscle improvement also contributed to ventilatory and cardiac performances profile changes.

Keywords: Pulmonary rehabilitation; Cardiopulmonary exercise testing; COPD; Dynamic hyperinflation; Exercise

\section{Introduction}

Chronic obstructive pulmonary disease (COPD) promotes structural changes in the lung parenchyma, including remodeling and airway obstruction, reducing lung elastic recoil. These changes interfere with the structures that keep airways opened during expiration, promoting dynamic hyperinflation [1,2].

Dynamic hyperinflation directly affects the cardiovascular system. The ventricular filling is impaired, causing small end-diastolic volumes, with reduction of the intrathoracic blood volume index, end-diastolic volume in the left and right ventricles, and systolic volume $[3,4]$. The performances of both ventricles are affected by a low preload caused by thoracic hypovolemia due to pulmonary hyperinflation [5].

Skeletal muscle system is also affected by COPD. Eliason et al. [6] observed that airway obstruction severity determines lower muscle capillarization, especially in type I fibers. This lower muscle perfusion, also influences muscle morphology. Gosker et al. [7] detected a lower mitochondrial density in the vastus lateralis of COPD patients, a fact that contributes to reduction of muscle oxidative capacity, with consequent loss of performance and premature fatigue. Less efficient muscles generates higher ventilatory demand, which promotes a vicious cycle.

The major aim of this study was to investigate the effects of a pulmonary rehabilitation program, based on physical exercise, on ventilatory and cardiac performances profile.

\section{Methods}

This is a 5 cases report study.

\section{Sample}

5 moderate to severe COPD patients evaluated in our exercise physiology laboratory, who met the following inclusion criteria: 1) absence of cardiac diseases and 2) absence of locomotor limitations that could impair exercise test evaluation or exercise program were recruited.

\section{Evaluation protocol design}

The patients underwent anthropometric assessment (height, weight and body mass index), followed by one maximum voluntary contraction muscle test, lung function test by spirometry and a cardiopulmonary exercise test. The entire evaluation occurred in a single day. Cardiopulmonary exercise test was repeated after intervention.

\section{Lung function test}

The technical procedure, acceptance criteria, reproducibility and interpretative values, as well as the standardization and equipment, followed the recommendations of the American Thoracic Society/ European Respiratory Society [8]. The equipment used was the Koko PFT (PDS Instrumentation, Inc. Louisville, Colorado, USA) coupled to a microcomputer, and it was calibrated daily. We considered the forced expiratory volume in 1 second $\left(\mathrm{FEV}_{1}\right)$, the forced vital capacity (FVC) and the $\mathrm{FEV}_{1} / \mathrm{FVC}$ ratio. The highest values were considered for analysis and compared to validated reference values for the Brazilian population $[9,10]$

\section{Cardiopulmonary exercise test}

The technical procedures followed the American Thoracic Society/

${ }^{*}$ Corresponding author: Murillo Frazão, Maria Caetano Fernandes de Lima St., 225, Tambauzinho, João Pessoa-PB, ZIP code: 58042-050, Brazil, Tel: +5583993622322; E-mail: murillo.frazao@gmail.com

Received January 18, 2016; Accepted February 04, 2016; Published February 09, 2016

Citation: Frazão M, Frazão W (2016) Pulmonary Rehabilitation Alters Ventilatory and Cardiac Performances Profile during Exercise in Moderate to Severe Copd: 5 Cases Report. J Pulm Respir Med 6: 320. doi:10.4172/2161-105X.1000320

Copyright: $\odot 2016$ Frazão M, et al. This is an open-access article distributed under the terms of the Creative Commons Attribution License, which permits unrestricted use, distribution, and reproduction in any medium, provided the original author and source are credited. 
Citation: Frazão M, Frazão W (2016) Pulmonary Rehabilitation Alters Ventilatory and Cardiac Performances Profile during Exercise in Moderate to Severe Copd: 5 Cases Report. J Pulm Respir Med 6: 320. doi:10.4172/2161-105X.1000320

Page 2 of 3

American College of Chest Physicians [10] guidelines for cycle ergometer testing. The CPET was performed on an electronically braked cycle ergometer, using Inbrasport CG-04 (Inbrasport, Porto Alegre, Rio Grande do Sul, Brazil). Each subject performed a ramp protocol, starting with unload pedaling and the work rate increment was individually selected (5-10 W/min) up to the limit of tolerance. Subjects were strongly encouraged by verbal stimuli to achieve maximum effort. The VO2000 (MedGraphics, St. Paul, Minnesota, USA) was used for gas analysis and it was calibrated daily according to the manufacturer's instructions. The Onyx 9500 pulse oximeter (NONIN, Plymouth, Minnesota, USA) was used for oxygen saturation analysis.

\section{CPET analysis}

Through CPET data, the following variables were analyzed: peak exercise oxygen saturation $\left(\mathrm{SpO}_{2}\right)$; peak heart rate; breathing reserve (BR); respiratory exchange ratio (RER), exercise duration; work rate (WR); oxygen consumption $\left(\mathrm{VO}_{2}\right)$; ventilation (VE) and oxygen pulse $\left(\mathrm{PuO}_{2}\right)$. The data was collected at every 10 seconds of ramp protocol. After collection, the data was adjusted by a filter (mean of 7 points) to avoid noises. The highest value of the last 30 seconds of collection was considered the $100 \% \mathrm{WR}$ value. The highest value of the 30 seconds of collection at half time test duration was considered the $50 \% \mathrm{WR}$ value.

\section{Pulmonary rehabilitation program}

All the patients were submitted to 8 weeks (5 sessions/week) exercise program. All patients performed 30 minutes of aerobic training (treadmill/cycle ergometer in alternate days) at $80 \%$ peak $\mathrm{VO}_{2}$ achieved at initial CPET and 5 resistance exercises (lower limb/upper limb in alternate days) starting at $30 \%$ achieved on initial maximum voluntary contraction and increasing $1 \mathrm{~kg}$ per week (until patient's limit).

\section{Statistical analysis}

The sample normality was analyzed using the Shapiro-Wilk test (which demonstrated a very small number to calculate). It was used Levene's test to analyze the homogeneity of the sample, and to evaluate the differences between measurements the paired T test was used. A statistical significance value of $\mathrm{p}<0.05$ was set for all analyzes by using the GraphPad Prism 6.0 software.

\section{Results}

\section{Clinical aspects}

Patients spirometric and anthropometric values and basic exercise characteristics are presented in Table 1.

\section{Ventilatory and cardiac consumption}

As demonstrated in Figure 1, pulmonary rehabilitation promoted no significant difference in ventilatory consumption at $0 \%$ work rate $(51.94 \pm 13.26$ vs. $44.17 \pm 15.04 \%, \mathrm{p}>0.05)$ and $50 \%$ work rate $(37.53 \pm 11.50$ vs. $26.86 \pm 6.64 \%, \mathrm{p}>0.05)$, but promoted significant difference at $100 \%$ work rate $(10.53 \pm 5.32$ vs. $28.97 \pm 12.07 \%, \mathrm{p}<0.05)$. Pulmonary rehabilitation also promoted no significant difference in cardiac consumption at $0 \%$ work rate ( $43.86 \pm 19.65$ vs. $38.29 \pm 14.88 \%$, $\mathrm{p}>0.05)$; at $50 \%$ work rate $(46.10 \pm 19.86$ vs. $38.83 \pm 8.04 \%, \mathrm{p}>0.05)$, but promoted significant difference at $100 \%$ work rate (10.04 $\pm 1.80 \mathrm{vs.}$ $22.88 \pm 10.36 \%, \mathrm{p}<0.05)$.

\section{Ventilatory and cardiac performances profile}

There was no significant difference in ventilation at $0 \% \mathrm{WR}(10.7$ \pm 3.8 vs. $11.9 \pm 5.1 \mathrm{~L} / \mathrm{min}, \mathrm{p}>0.05)$ and at $50 \% \mathrm{WR}(18.4 \pm 3.7$ vs. 19.2 $\pm 5.2 \mathrm{~L} / \mathrm{min}, \mathrm{p}>0.05)$ however pulmonary rehabilitation increased

\begin{tabular}{|c|c|}
\hline Age (years) & $74.2 \pm 8.5$ \\
\hline $\mathrm{BMI}\left(\mathrm{Kg} / \mathrm{m}^{2}\right)$ & $26.4 \pm 3.3$ \\
\hline Gender (M/F) & $3 / 2$ \\
\hline $\mathrm{FVC}(\mathrm{L})$ & $1.45 \pm 0.34$ \\
\hline FVC (\%pred) & $49.0 \pm 4.6$ \\
\hline $\mathrm{FEV}_{1}(\mathrm{~L})$ & $0.90 \pm 0.32$ \\
\hline $\mathrm{FEV}_{1}(\%$ pred $)$ & $42.3 \pm 16.1$ \\
\hline $\mathrm{FEV}_{1} / \mathrm{FVC}$ & $0.63 \pm 0.17$ \\
\hline RER & $1.02 \pm 0.10$ \\
\hline Peak execise $\mathrm{SpO}_{2}(\%)$ & $90.8 \pm 7.3$ \\
\hline Peak heart rate (bpm) & $119.2 \pm 14.3$ \\
\hline CPET duration (s) & $331.2 \pm 132.3$ \\
\hline Ramp protocol (w/min) & $6.9 \pm 1.1$ \\
\hline
\end{tabular}

Table 1: Lung function, anthropometric and basic exercise characteristics. BMI:

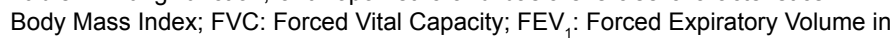
the $1^{\text {st }}$ Second; FEV /FCV: Tiffenau Index; \%pred: Percentage of Predicted, RER Respiratory Exchange Ratio, $\mathrm{SpO}_{2}$ : Oxygen Saturation, CPET: Cardiopulmonary Exercise Test.

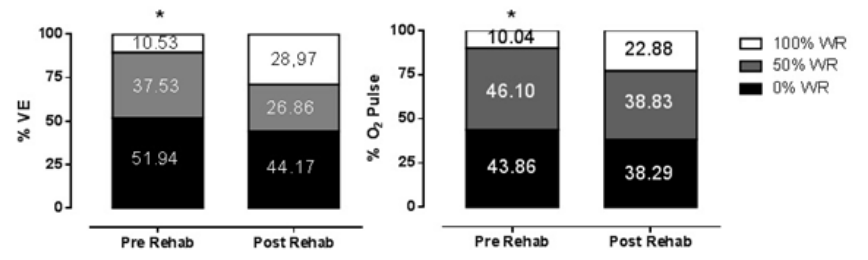

Figure 1: Ventilatory and cardiac consumption. VE: Ventilation; WR: Work Rate; Rehab: Pulmonary Rehabilitation; ${ }^{*} p<0.055$.

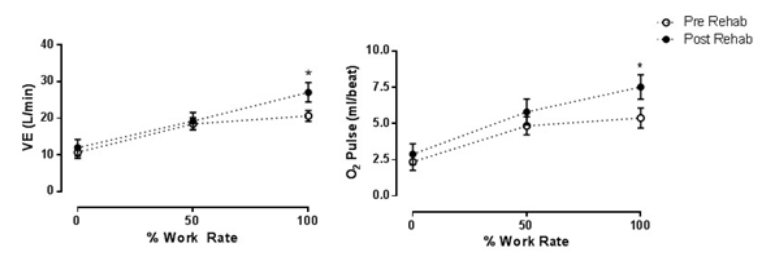

Figure 2: Ventilatory and cardiac performances profile. VE: Ventilation; Rehab: Pulmonary Rehabilitation; ${ }^{*} p<0.055$.

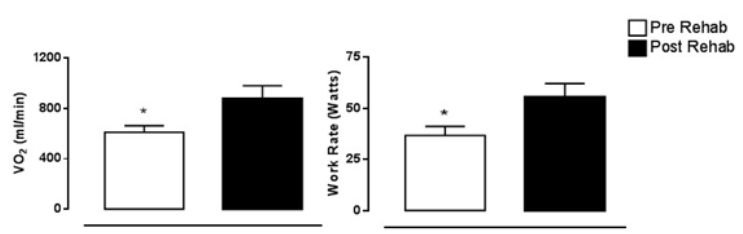

Figure 3: Metabolic and functional capacity. $\mathrm{VO}_{2}$ : Oxygen Consumption; WR: Work Rate; Rehab: Pulmonary Rehabilitation; ${ }^{*} p<0.055$.

ventilation at $100 \% \mathrm{WR}(20.6 \pm 3.3$ vs. $27.1 \pm 5.9 \mathrm{~L} / \mathrm{min}, \mathrm{p}<0.05)$. There was no significant difference in oxygen pulse at $0 \% \mathrm{WR}(2.4 \pm 1.3$ vs. 2.9 $\pm 1.3 \mathrm{ml} /$ beat, $\mathrm{p}>0.05)$ and at $50 \% \mathrm{WR}(4.8 \pm 1.4 \mathrm{vs} .5 .8 \pm 1.9 \mathrm{ml} /$ beat, $\mathrm{p}>0.05)$ however pulmonary rehabilitation increased oxygen pulse at $100 \%$ WR $(5.4 \pm 1.6$ vs. $7.5 \pm 1.9 \mathrm{ml} /$ beat, $\mathrm{p}<0.05)$ (Figure 2).

\section{Metabolic and functional capacity}

Pulmonary rehabilitation increased $\mathrm{VO}_{2}(610 \pm 110$ vs. $880 \pm 230$ $\mathrm{ml} / \mathrm{min}, \mathrm{p}<0.05)$ and work rate $(36.8 \pm 9.8$ vs. $55.6 \pm 14.8 \mathrm{~W}, \mathrm{p}<0.05)$ (Figure 3). 
Citation: Frazão M, Frazão W (2016) Pulmonary Rehabilitation Alters Ventilatory and Cardiac Performances Profile during Exercise in Moderate to Severe Copd: 5 Cases Report. J Pulm Respir Med 6: 320. doi:10.4172/2161-105X.1000320

Page 3 of 3

\section{Discussion}

The present study demonstrated that a 8 week pulmonary rehabilitation program: 1) increases ventilatory and cardiac performances; 2) changes ventilatory and cardiac reserves consumption and 3) increases functional capacity.

\section{VE}

Before pulmonary rehabilitation, COPD patients presented almost a plateau on ventilation graph after $50 \% \mathrm{WR}$, which suggests dynamic hyperinflation [11]. After pulmonary rehabilitation, ventilation graph no longer presents plateau feature, suggesting dynamic hyperinflation reduction. Georgiadou et al. [12] demonstrated that in the postrehabilitation period, at identical work rates, significant reductions were observed in end expiratory lung volume and ventilatory demand, indicating reduction in dynamic hyperinflation, once that inspiratory reserve volume was significantly increased, what corroborates with our data.

\section{Oxygen pulse}

Dynamic hyperinflation reduction improves oxygen pulse [13] and reduces dynamic cardiac constraints. Cardiac mechanic is improved by reducing left ventricular afterload that is increased due to the high intrathoracic pressure swings needed to overcome the high elastic and resistive loads in COPD during exercise [14]. Dynamic hyperinflation reduction also increases blood return and preload, optimizing cardiac performance.

\section{WR}

Metabolic inefficient peripheral muscles have a reduced oxidative capacity, consequently, glycolytic ways of energy generation are early activated. As a result of glycolytic ways activation, extra $\mathrm{CO}_{2}$ from lactic acid buffering induces a higher ventilatory demand. Vogiatzis et al. [15] studied morphological and biochemical adaptations caused by interval training on vastus lateralis during a 10-week training. Muscle biopsy analysis showed an increase in cross-sectional area of both fiber type I and of type II fibers, and increased enzyme activity, reflecting an increase of $19 \%$ in muscle performance. Our data demonstrates increase in work rate, suggesting improvement on peripheral muscle oxidative capacity. This probable morphological change hypothetically promoted reduction in ventilatory demand/dynamic hyperinflation, which probably contributed to ventilation and oxygen pulse increases.

$\mathrm{VO}_{2}$

Oxygen consumption increased as a result of multiple system adaptation to exercise. This is an expected result, previously described in a large number of studies.

\section{Conclusions}

A 8 week pulmonary rehabilitation program improved ventilatory and cardiac performances, probably as a result of dynamic hyperinflation reduction. Peripheral muscle improvement also contributed to ventilatory and cardiac performances profile changes.

\section{References}

1. Lindberg A, Jonsson AC, Rönmark E, Lundgren R, Larsson LG, et al. (2005) Prevalence of chronic obstructive pulmonary disease according to BTS, ERS GOLD and ATS criteria in relation to doctor's diagnosis, symptoms, age, gender, and smoking habits. Respiration 72: 471-479.

2. Celli BR, MacNee W; ATS/ERS Task Force (2004) Standards for the diagnosis and treatment of patients with COPD: a summary of the ATS/ERS position paper. Eur Respir J 23: 932-946.

3. Jörgensen K, Müller MF, Nel J, Upton RN, Houltz E, et al. (2007) Reduced intrathoracic blood volume and left and right ventricular dimensions in patients with severe emphysema: an MRI study. Chest 131: 1050-1057.

4. Jörgensen K, Houltz E, Westfelt U, Ricksten SE (2007) Left ventricular performance and dimensions in patients with severe emphysema. Anesth Analg 104: 887-892.

5. Barr RG, Bluemke DA, Ahmed FS, Carr JJ, Enright PL, et al. (2010) Percent emphysema, airflow obstruction, and impaired left ventricular filling. $\mathrm{N}$ Engl $\mathrm{J}$ Med 362: 217-227.

6. Eliason G, Abdel-Halim SM, Piehl-Aulin K, Kadi F (2010) Alterations in the muscle-to-capillary interface in patients with different degrees of chronic obstructive pulmonary disease. Respir Res 11: 97

7. Gosker HR, Hesselink MK, Duimel H, Ward KA, Schols AM (2007) Reduced mitochondrial density in the vastus lateralis muscle of patients with COPD. Eur Respir J 30: 73-79.

8. Miller MR, Hankinson J, Brusasco V, Burgos F, Casaburi R, et al. (2005) Standardisation of spirometry. Eur Respir J 26: 319-338.

9. Pereira CA, Sato T, Rodrigues SC (2007) New reference values for forced spirometry in white adults in Brazil. J Bras Pneumol 33: 397-406.

10. American Thoracic Society; American College of Chest Physicians (2003) ATS/ ACCP Statement on Cardiopulmonary Exercise Testing. Am J Respir Crit Care Med 167: 211-277.

11. O'Donnell DE, Webb KA (2008) The major limitation to exercise performance in COPD is dynamic hyperinflation. J Appl Physiol (1985) 105: 753-755.

12. Georgiadou O, Vogiatzis I, Stratakos G, Koutsoukou A, Golemati S, et al (2007) Effects of rehabilitation on chest wall volume regulation during exercise in COPD patients. Eur Respir J 29: 284-291.

13. Come CE, Divo MJ, San José Estépar R, Sciurba FC, Criner GJ, et al. (2012) Lung deflation and oxygen pulse in COPD: results from the NETT randomized trial. Respir Med 106: 109-119.

14. Montes de Oca M, Rassulo J, Celli BR (1996) Respiratory muscle and cardiopulmonary function during exercise in very severe COPD. Am J Respir Crit Care Med 154: 1284-1289.

15. Vogiatzis I, Terzis G, Nanas S, Stratakos G, Simoes DC, et al. (2005) Skeletal muscle adaptations to interval training in patients with advanced COPD. Chest 128: 3838-3845. 